\title{
On possibility of replacement of saturated steam with hot water at circulating heating of fuel oil
}

\author{
Valery Petrushchenkov ${ }^{1, *}$, and Michail Shcheglov ${ }^{2}$ \\ ${ }^{1}$ Peter the Great St. Petersburg Polytechnic University, St. Petersburg, Russian Federation \\ ${ }^{2}$ Mechanical Factory “Enerprom”, St. Petersburg, Russian Federation
}

\begin{abstract}
Circulating heating of fuel oil in railway tanks is performed, as a rule, with the help of saturated steam by preparing a heating flow of fuel oil with a temperature of about $80 \ldots 90^{\circ} \mathrm{C}$. For the operation services of fuel oil storages, it is interesting to consider replacing steam with hot water. The behavior of the existing system of circulating heating of fuel oil of M100 brand when changing the heating medium for the heater of fuel oil flow in the form of a plate heat exchanger is considered. The initial temperature of hot water is assumed to be equal to the design temperature of $115^{\circ} \mathrm{C}$ in the steam-fuel heat exchanger. The values of the thermal capacity of the heater flow of fuel oil, fuel oil consumption, flow rate and the temperature of the heating water flow at the outlet of the heat exchanger are defined depending on the temperature of the heated fuel oil in the range of $80 \ldots 90^{\circ} \mathrm{C}$. Reducing the temperature of fuel oil at the outlet of the heat exchanger from 90 to $80^{\circ} \mathrm{C}$ allows to increase its capacity by $30.1 \%$, that is, to accelerate the heating of fuel oil in the tank and reduce the time of its discharge.
\end{abstract}

\section{Introduction}

The method of local circulating heating of fuel oil is widely used on unloading racks for discharge of different grades of fuel oil from railway tanks. Typically, the coolant used saturated steam received from the district and industrial heating steam boiler. The idea of replacing steam with hot water is very attractive for fuel oil storage operation services. The use of its own block-type hotwater boiler as an alternative to purchasing steam from external sources will make the project pay off quickly provided that the required temperature of the heating oil flow and its flow rate are maintained. Changing the water temperature in the heat exchanger, preparing a hot flow of fuel oil for the heating zone in the tank, looks a significant obstacle to the implementation of such a transition in practice. Therefore, the computational study of the possibility and efficiency of replacing the heating steam coolant with water is of interest.

The costs of such reconstruction will be minimal if we consider the preservation of the steam-fuel heat exchanger heating the circulating flow of fuel oil. It is obvious that it is necessary to calculate the heat transfer process and pressure losses in a given heat exchanger taking into account the new conditions: the replacement of saturated water vapor to the hot water flow, changes in the temperature levels in both paths and the corresponding thermophysical characteristics of the heat carriers.
A system of local circulating heating of fuel oil is studied in detail in numerical experiments, but only in one of its elements - in a storage tank or a railway tank [1-11]. In the specified works influence of position of nozzles, their quantity on process of mixing of hot jets of fuel oil with colder masses is defined. It is also of interest to study the influence on the heat exchanger capacity of the heating oil heating system of the type of heating medium, the permissible temperature range coolants and flow regime.

In [12] a system study was performed for the turbulent motion of M100 fuel oil in a plate heat exchanger in an approximate version that does not take into account the influence of changes in the characteristic flow temperatures on the thermal properties of fuel oil. Turbulent movement of fuel oil in the channels of the plate heat exchanger is likely to occur only at high temperatures of low-viscosity fuel oil and the presence of turbulent inserts. More realistic and interesting for practice is the laminar flow of fuel oil in the heat exchanger. It is of interest to consider the consequences of replacing the heating medium from saturated steam to water for the existing heat exchanger of the circulating heating system of fuel oil.

Figure 1 shows the heating scheme of fuel oil [13].

In the heat exchanger 4 , a hot flow of fuel oil is prepared, which provides local heating of fuel oil in the tank in the zone of its discharge. Part of this flow through line 7 is fed into the suction line of the fuel oil circulation pump 5 for mixing with the fuel oil flow

\footnotetext{
* Corresponding author: pva38@mail.ru
} 
discharged from the tank through the branch pipe 2 . Local heating of fuel oil in the tank is performed by supplying the fuel oil flow heated in the heat exchanger 4 to the fuel oil intake area from the tank through the branch pipe 3.

The transfer from heating steam to hot water was successfully carried out in 2014 year for the existing system of circulating heating oil unloading overpass LLC “PETER-NORD” in St. Petersburg. Reconstruction of the steam-oil plate heat exchanger M15-MFG produced by "Alfa Laval Potok" was not needed, the number of plates did not change.

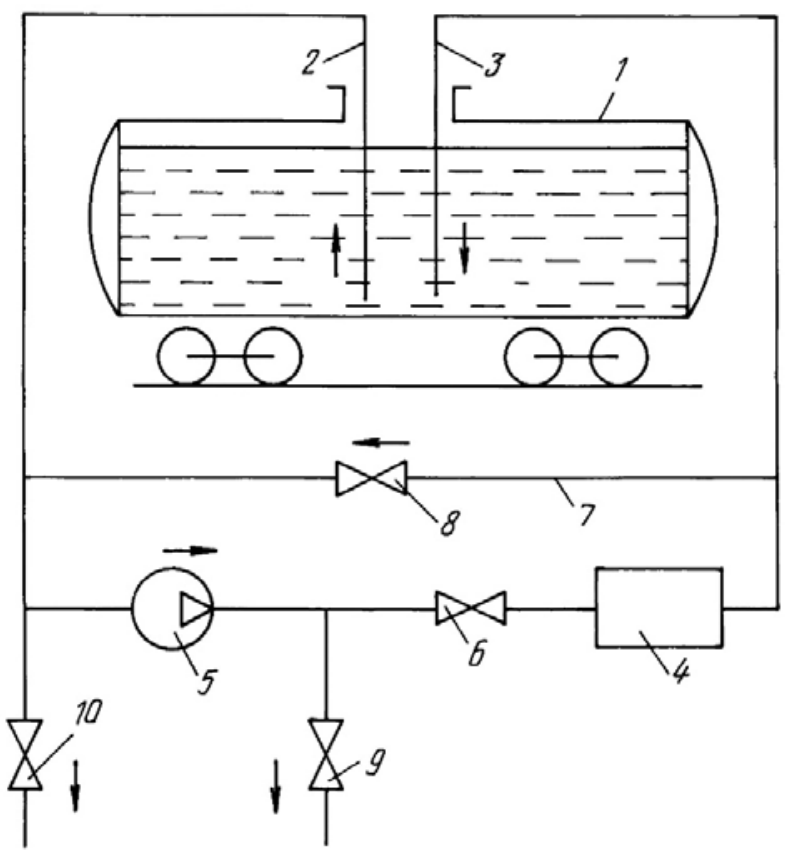

Fig. 1. Scheme of circulating heating of fuel oil when draining it from the tank. 1 - fuel oil tank, 2 - fuel oil selection line for heating, 3 - heated fuel oil supply line for local heating, 4 plate heat exchange, 5 - circulation pump, 7 - bypass line, 6, 8, 9, 10 - shut-off and control valves.

The calculations performed in this article are focused on the characteristic parameters of the said heating oil system with their generalization to other designs of heat exchangers and for different flow regimes.

Project circulation the heating of fuel oil M100 brand was provided using saturated steam absolute pressure of 1.7 bar and a temperature of $115^{\circ} \mathrm{C}$. In the calculation are used the characteristics of the steam-oil plate heat exchanger M15-MFG manufactured by JSC “Alfa Laval Potok”, is given in the manufacturer's specifications for the heat exchanger. The estimated consumption of heating steam named parameters equal $3396 \mathrm{~kg} / \mathrm{h}$ pressure drop in the steam path equal to $1.11 \mathrm{kPa}$. The capacity of the fuel oil heater in the design mode is 2093 $\mathrm{kW}$. The calculated excess pressure tract heating medium 3.5 bar, test pressure 4.6 bar. The value of the calculated flow rate of heated fuel oil grade M100 is $77000 \mathrm{~kg} / \mathrm{h}$. The temperature of the oil at the inlet of the heat exchanger $40^{\circ} \mathrm{C}$, outlet $90^{\circ} \mathrm{C}$. Pressure losses in the path of fuel oil equal to $31.9 \mathrm{kPa}$. The excess design pressure on the fuel oil path is 9 bar, the test pressure is 11.7 bar. The scheme of movement of heat carrierscounterflow. The heating surface area of the heat exchanger is $146.3 \mathrm{~m}^{2}$, the heat transfer coefficient is $324 \mathrm{~W} /\left(\mathrm{m}^{2} \cdot \mathrm{K}\right)$, pollution is not taken into account. Number of strokes for each coolant 1.

Consider replacing the heating medium in the form of saturated water steam temperature $115^{\circ} \mathrm{C}$ an absolute pressure of 1.7 bar in the hot water temperature at the inlet to the heat exchanger $115^{\circ} \mathrm{C}$, a pressure of $3.5 \mathrm{bar}$ in an existing project steam-oil heat exchanger. The countercurrent scheme of fuel oil and water movement is preserved. To heat the water cooled in the heat exchanger, it is provided to use a water-heating heat-tube boiler "THERMOTECHNIK" TT-100 with a small hydraulic resistance.

The hot water boiler has the following characteristics. The nominal boiler capacity of $2500 \mathrm{~kW}$, the maximum excess water pressure in the boiler is 6 bar, maximum water temperature at the boiler outlet $115^{\circ} \mathrm{C}$, minimum inlet temperature to the boiler $70^{\circ} \mathrm{C}$. Pressure losses in the water path at nominal power of the boiler and the water flow rate $143 \mathrm{~m}^{3} / \mathrm{h}$, corresponding to heating water for $15^{\circ} \mathrm{C}$, is $15 \mathrm{kPa}$.

\section{Methods}

Replacement of the heating coolant of saturated steam with hot water is accompanied by a change in the heat capacity of the heat exchanger, the consumption of fuel oil, its outlet temperature. The coefficient of heat transfer at condensation steam and hot water flow has a value of about $5000 \mathrm{~W} /\left(\mathrm{m}^{2} \cdot \mathrm{K}\right)$, whereas the heat transfer coefficient of fuel oil M100 brand at the level of 300 $\mathrm{W} /\left(\mathrm{m}^{2} \cdot \mathrm{K}\right)$. This ratio allows with sufficient approximation for practice to neglect the effect of heat transfer of the heating medium on the heat transfer coefficient of the heat exchanger of the circulating heating system of fuel oil. In this case $k \approx \alpha_{\mathrm{f}}$. In the calculations adopted the temperature of the heating water flow at the inlet of the heat exchanger equal to the temperature of saturated steam model $\mathrm{t}_{\mathrm{w}}^{\prime}=\mathrm{t}_{\mathrm{s}}=115^{\circ} \mathrm{C}$, the output $t_{w}^{\prime \prime}=100^{\circ} \mathrm{C}$. The temperature of the circulating stream of fuel oil at the inlet of the heat exchanger is maintained in accordance with the design value $\mathrm{t}_{\mathrm{f}}^{\prime}=40^{\circ} \mathrm{C}$, the output varies in a narrow range, ensuring local heating of cold fuel oil in the tank $\mathrm{t}_{\mathrm{f}}=80 \ldots 90^{\circ} \mathrm{C}$.

Changes in average temperatures and flow rates of heat carriers in both paths of the heater leads to a change in the heat capacity of the heat exchanger, as well as the temperature of water and fuel oil at the outlet. The calculated study of the influence of fuel oil temperature at the heater outlet on the change of all other characteristics of the system was performed. To this end, the system of equations of heat transfer of fuel oil, heat transfer, heat balance, mass conservation is solved taking into account the flow regime of fuel oil and the dependence of its thermal properties on temperature. 
A separate effect of changes in fuel oil velocities and its temperatures on the heat capacity of the heat exchanger is investigated. The results obtained for plate heat exchangers also apply to shell-and-tube heat exchangers widely used in heating oil systems.

\subsection{Calculations of the operation modes of a plate heat exchanger when used as a heating medium hot water with a temperature of $115^{\circ} \mathrm{C}$}

\subsubsection{Laminar flow regime of fuel oil.}

We define the capacity of the heat exchanger and the flow rate of oil through the heat exchanger for laminar flow of oil under the design values of the inlet temperature $t_{f}^{\prime}=40^{\circ} \mathrm{C}$, the output $t_{f}^{\prime \prime}=90^{\circ} \mathrm{C}$. The temperature of the water entering the heat exchanger $\mathrm{t}_{\mathrm{w}}^{\prime}=115^{\circ} \mathrm{C}$, at the outlet of the heat exchanger $\mathrm{t}_{\mathrm{w}}=100^{\circ} \mathrm{C}$.

The average logarithmic temperature difference taking into account the countercurrent scheme of the movement of heat carriers in this case will be equal to

$$
\Delta t_{\log }=\left[\left(t_{w}^{\prime \prime}-t_{f}^{\prime}\right)-\left(t_{w}^{\prime}-t_{f}^{\prime \prime}\right)\right] / \ln \frac{\left(t_{w}^{\prime \prime}-t_{f}^{\prime}\right)}{\left(t_{w}^{\prime}-t_{f}^{\prime \prime}\right)}=40^{\circ} \mathrm{C} \text {. }
$$

When using saturated steam with a temperature of $115^{\circ} \mathrm{C}$ as a heating coolant, the average temperature difference is equal to $\Delta \mathrm{t}_{\log }^{0}=45.51^{\circ} \mathrm{C}$.

The heat capacity of the heat exchanger when used as a heating flow of hot water with the specified temperatures will be determined by the temperature difference between the flows, as well as the heat transfer coefficient from the fuel oil. At given temperatures of the fuel oil heat transfer coefficient decreases due to the decrease in power of the heat exchanger due to the decrease in temperature difference between coolant and, consequently, reduce the consumption of fuel oil. The dependence of the heat transfer coefficient from the fuel oil on its velocity in the channels is assumed for the laminar flow regime. In the whole investigated range of parameters in the system of circulating heating of the unloading overpass of LLC "PETER-NORD" the Reynolds number Re in the fuel oil path is of the order of 1. The transition to a turbulent flow regime for plate heat exchangers is determined by the critical value $\mathrm{Re}_{\mathrm{cr}}=50$. In accordance with [14] for plate heat exchangers, the criterion equation of heat transfer in the laminar flow regime of fuel oil has the form

$$
\begin{gathered}
\mathrm{Nu}=0.63 \operatorname{Re}^{0.33} \operatorname{Pr}^{0.33}\left(\operatorname{Pr}_{\mathrm{f}} / \operatorname{Pr}_{\mathrm{w}}\right)^{0.25}, \\
\mathrm{k} \approx \alpha_{\mathrm{f}} \square \mathrm{w}^{0.33} .
\end{gathered}
$$

The heat balance equation for fuel oil and the heat transfer equation for heating fuel oil with steam in a heat exchanger with a given geometry have the form:

$$
\mathrm{Q}_{0}=\mathrm{G}_{\mathrm{f} 0} \mathrm{C}_{\mathrm{pf} 0}\left(\mathrm{t}_{\mathrm{f} 0}^{\prime \prime}-\mathrm{t}_{\mathrm{f}}^{\prime}\right)=\mathrm{FA}\left(\mathrm{t}_{\mathrm{avf} 0}\right) \mathrm{G}_{\mathrm{f} 0}^{0.33} \Delta \mathrm{t}_{\log }^{0},
$$

for heating fuel oil with water:

$$
\mathrm{Q}=\mathrm{G}_{\mathrm{f}} \mathrm{c}_{\mathrm{pf}}\left(\mathrm{t}_{\mathrm{f}}^{\prime \prime}-\mathrm{t}_{\mathrm{f}}^{\prime}\right)=\mathrm{FA}\left(\mathrm{t}_{\mathrm{avf}}\right) \mathrm{G}_{\mathrm{f}}^{0.33} \Delta \mathrm{t}_{\text {log }} .
$$

Index 0 corresponds to the parameters when heating fuel oil with saturated steam.

For the given temperatures of fuel oil and heating water given above, the heat capacity of the heat exchanger and the fuel oil flow through the heat exchanger as a result of solving the system of equations (1)-(4) will be part of the corresponding values when heated with steam:

$$
\overline{\mathrm{Q}}=\overline{\mathrm{G}}_{\mathrm{f}}=\left(\Delta \mathrm{t}_{\log } / \Delta \mathrm{t}_{\log }^{0}\right)^{1 / 0.67}=0.824 \text {. }
$$

As can be seen from the above ratio (5), the heat capacity of the heat exchanger and fuel oil consumption when replacing steam with hot water at specified temperatures fall by $17.6 \%$.

We investigate the behavior of the circulating heating system of fuel oil when replacing the heating coolant for the temperature of the heated fuel oil in the range of $80-90^{\circ} \mathrm{C}$. In this case the process of local heating of fuel oil in the tank for its discharge will be preserved. The most interesting parameter is the power of the heat exchanger.

At first we neglect the change in the function $\mathrm{A}\left(\mathrm{t}_{\mathrm{avf}}\right) / \mathrm{C}_{\mathrm{pf}}$ due to a small change in its argument in the temperature range $60 \ldots 65^{\circ} \mathrm{C}$ to receive the simple and clear dependences.

If heated with water to keep the temperature difference $\Delta \mathrm{t}_{\log }=\Delta \mathrm{t}_{\log }^{0}$, the temperature of the fuel oil entering the heat exchanger equal to $40^{\circ} \mathrm{C}$, the temperature of the fuel oil at the outlet of the heat exchanger equal $81.43^{\circ} \mathrm{C}$, relative consumption of fuel oil is equal to

$$
\overline{\mathrm{G}}_{\mathrm{f}}=\left[\frac{\left(\mathrm{t}_{\mathrm{f} 0}^{\prime \prime}-\mathrm{t}_{\mathrm{f}}^{\prime}\right)}{\left(\mathrm{t}_{\mathrm{f}}^{\prime \prime}-\mathrm{t}_{\mathrm{f}}^{\prime}\right)}\right]^{1 / 0.67}=(50 / 41.43)^{1.5}=1.326 .
$$

The heat capacity of the heat exchanger will be determined:

$$
\overline{\mathrm{Q}}=\left(\overline{\mathrm{G}}_{\mathrm{f}}\right)^{0.33}=1.098 \text {. }
$$

Thus, in accordance with (6) and (7) maintaining a temperature difference between the hot water flow and oil temperature of oil supplied to the heating zone is reduced to $81.43^{\circ} \mathrm{C}$, while fuel oil consumption increases almost $33 \%$, the thermal power applied in a volume of cold fuel oil tanks increased by $10 \%$.

Table 1 shows the results of calculations for different heating oil $\mathrm{t}_{\mathrm{f}}^{\prime \prime}$ in the range of $80^{\circ} \mathrm{C}$ up to $90^{\circ} \mathrm{C}$ in accordance with the dependencies (8) for fuel oil consumption, power of the heat exchanger, and the ratios (9) for water consumption against the steam flow, the heat transfer coefficient in the oil tract.

$$
\begin{gathered}
\overline{\mathrm{G}}_{\mathrm{f}}=\left\{\left[\left(\mathrm{t}_{\mathrm{f} 0}^{\prime \prime}-\mathrm{t}_{\mathrm{f}}^{\prime}\right) \Delta \mathrm{t}_{\log }\right] /\left[\left(\mathrm{t}_{\mathrm{f}}^{\prime \prime}-\mathrm{t}_{\mathrm{f}}^{\prime}\right) \Delta \mathrm{t}_{\log }^{0}\right]\right\}^{1.5}, \\
\overline{\mathrm{Q}}=\overline{\mathrm{G}}_{\mathrm{f}}\left(\mathrm{t}_{\mathrm{f} 0}^{\prime \prime}-\mathrm{t}_{\mathrm{f}}^{\prime}\right) /\left(\mathrm{t}_{\mathrm{f}}^{\prime \prime}-\mathrm{t}_{\mathrm{f}}^{\prime}\right) \\
\overline{\mathrm{G}}_{\mathrm{s}}=1.0, \quad \overline{\mathrm{G}}_{\mathrm{w}}=\mathrm{G}_{\mathrm{w}} / \mathrm{G}_{\mathrm{s}}=\overline{\mathrm{Q}} \mathrm{r} /\left[\mathrm{c}\left(\mathrm{t}_{\mathrm{w}}^{\prime}-\mathrm{t}_{\mathrm{w}}^{\prime \prime}\right)\right], \\
\bar{\alpha}_{\mathrm{f}}=\alpha_{\mathrm{f}} / \alpha_{\mathrm{f} 0}=\mathrm{Nu} / \mathrm{Nu}_{0} \approx \overline{\mathrm{G}}_{\mathrm{f}}^{0.33} .
\end{gathered}
$$


Here c - specific mass heat of water, $r$ - the specific mass heat of water vaporization at the operating pressure of steam.

When the temperature of the oil at the outlet of the heat exchanger is $84.32^{\circ} \mathrm{C}$ the consumption of fuel oil increased by $12.8 \%$, the thermal capacity of the heat exchanger remains unchanged.

The maximum increase in the heat exchanger power reaches $15.1 \%$ with an increase in fuel oil consumption by $43.8 \%$ and a decrease in fuel oil temperature to $80^{\circ} \mathrm{C}$.

The estimates show that the replacement of the heating medium from steam to water with a temperature at the inlet to the heat exchanger $115^{\circ} \mathrm{C}$, output $100^{\circ} \mathrm{C}$ allows you to provide heating of the circulation flow of fuel oil to $80 \ldots 90^{\circ} \mathrm{C}$ with the change of the heat capacity of the system in the range of $+15 \ldots-18 \%$. Moreover, the fuel oil consumption and heat capacity of the heat exchanger are very dependent on the temperature of the fuel oil at the outlet of the heat exchanger.

Table 1. The results of approximate calculations for water heating $\left(115 \ldots 100^{\circ} \mathrm{C}\right)$ for laminar flow of the fuel oil in the channels of a plate heat exchanger.

\begin{tabular}{|c|c|c|c|c|c|}
\hline \multicolumn{6}{|c|}{ Saturated steam heating $\mathbf{t}_{\mathbf{s}}=\mathbf{1 1 5}^{\circ} \mathbf{C}, \mathbf{t}_{\mathbf{f}}^{\prime}=\mathbf{4 0}{ }^{\circ} \mathbf{C}$} \\
\hline $\mathbf{t}_{\mathbf{f}}{ }^{\prime \prime},{ }^{\circ} \mathbf{C}$ & $\Delta \mathbf{t}_{\text {log }},{ }^{\circ} \mathbf{C}$ & $\overline{\mathbf{G}}_{\mathbf{f}}$ & $\overline{\mathbf{Q}}$ & $\overline{\mathbf{G}}_{\mathbf{s}}$ & $\overline{\boldsymbol{\alpha}}_{\mathbf{f}}$ \\
\hline 90 & 45.51 & 1.0 & 1.0 & 1.0 & 1.0 \\
\hline \multicolumn{7}{|c|}{ Hot water heating $\mathbf{t}_{\mathbf{w}}^{\prime}=\mathbf{1 1 5}^{\circ} \mathbf{C}, \mathbf{t}_{\mathbf{w}}^{\prime \prime}=\mathbf{1 0 0}^{\circ} \mathbf{C}$} \\
\hline $\mathbf{t}_{\mathbf{f}},{ }^{\circ} \mathbf{C}$ & $\Delta \mathbf{t}_{\text {log }},{ }^{\circ} \mathbf{C}$ & $\overline{\mathbf{G}}_{\mathbf{f}}$ & $\overline{\mathbf{Q}}$ & $\overline{\mathbf{G}}_{\mathbf{w}}$ & $\overline{\boldsymbol{\alpha}}_{\mathbf{f}}$ \\
\hline 80 & 46.38 & 1.438 & 1.151 & 40.23 & 1.127 \\
\hline 81.43 & 45.51 & 1.326 & 1.098 & 38.38 & 1.098 \\
\hline 82 & 45.17 & 1.285 & 1.079 & 37.71 & 1.086 \\
\hline 84 & 43.92 & 1.149 & 1.011 & 35.33 & 1.047 \\
\hline 84.32 & 43.71 & 1.128 & 1.0 & 34.96 & 1.041 \\
\hline 86 & 42.64 & 1.028 & 0.946 & 33.06 & 1.009 \\
\hline 86.5 & 42.31 & 1.0 & 0.930 & 32.50 & 1.000 \\
\hline 88 & 41.33 & 0.920 & 0.883 & 30.88 & 0.973 \\
\hline 90 & 39.98 & 0.824 & 0.824 & 28.80 & 0.938 \\
\hline
\end{tabular}

From the data in table 1 it can be seen that the maximum power of the heat exchanger is $1.151 \times 2093=2409 \mathrm{~kW}$ and does not exceed the rated power of $2500 \mathrm{~kW}$ of the "THERMOTECHNIK" TT-100. The maximum flow rate of heating water is $136.6 \mathrm{t} / \mathrm{h}$. Experimentally measured water pressure losses on the heat exchanger in this case amounted to only $8 \mathrm{kPa}$.

The above estimates allow us to see the effect on the heating process of fuel oil when replacing steam with water, depending on the main factors associated with the change in fuel oil consumption for a given heat exchanger.

At the same time, these relations allow us to take into account the dependence of the thermal properties of fuel oil on its average temperature. In equations (3) and (4), the multipliers $\mathrm{A}\left(\mathrm{t}_{\mathrm{avf}}\right) / \mathrm{c}_{\mathrm{pf}}$ can be determined by taking into account the type of criterion equation (2). Analysis of the influence of the temperature of fuel oil M100 on its thermophysical properties [4] in the range of average temperatures of $60 \ldots 65^{\circ} \mathrm{C}$ showed that the thermal conductivity coefficient, density and heat capacity of fuel oil are practically unchanged. The kinematic viscosity and the Prandtl number change very considerably. After selecting the significant parameters that depend on the temperature, we have an additional dimensionless factor B for the average temperature head in the heat exchanger

$$
\mathrm{A}\left(\mathrm{t}_{\mathrm{avf}}\right) / \mathrm{c}_{\mathrm{pf}} \square \mathrm{B}=\left(\frac{\mathrm{a}_{0}^{\mathrm{f}}\left(\mathrm{t}_{\mathrm{avf}}\right)}{\mathrm{a}^{\mathrm{f}}\left(\mathrm{t}_{\mathrm{avf}}\right)}\right)^{0.33} \cdot\left(\frac{\mathrm{Pr}_{\mathrm{f}}}{\operatorname{Pr}_{\mathrm{w}}}\right)^{0.25} .
$$

The system of equations (8) and (9) will be valid, taking into account the refinement of the relative fuel oil consumption

$$
\overline{\mathrm{G}}_{\mathrm{f}}=\left\{\mathrm{B}\left[\left(\mathrm{t}_{\mathrm{f} 0}^{\prime \prime}-\mathrm{t}_{\mathrm{f}}^{\prime}\right) \Delta \mathrm{t}_{\log }\right] /\left[\left(\mathrm{t}_{\mathrm{f}}^{\prime \prime}-\mathrm{t}_{\mathrm{f}}^{\prime}\right) \Delta \mathrm{t}_{\log }^{0}\right]\right\}^{1.5} .
$$

Table 2 shows the solution of the system of equations (2)-(4) taking into account the dependence of the properties of fuel oil on temperature [15].

Table 2. The results of calculations for water heating $\left(115 \ldots 100^{\circ} \mathrm{C}\right)$ for laminar flow of the fuel oil in the channels of a plate heat exchanger is based on the dependence of the properties of the fuel oil temperature.

\begin{tabular}{|c|c|c|c|c|c|c|}
\hline \multicolumn{7}{|c|}{ Saturated steam heating $\mathbf{t}_{\mathbf{s}}=\mathbf{1 1 5}^{\circ} \mathbf{C}, \mathbf{t}_{\mathbf{f}}^{\prime}=\mathbf{4 0}^{\circ} \mathbf{C}$} \\
\hline $\mathbf{t}_{\mathbf{f}},{ }^{\circ} \mathbf{C}$ & $\Delta \mathbf{t}_{\log },{ }^{\circ} \mathbf{C}$ & $\mathbf{B}$ & $\overline{\mathbf{G}}_{\mathbf{f}}$ & $\overline{\mathbf{Q}}$ & $\overline{\mathbf{G}}_{\mathbf{s}}$ & $\overline{\boldsymbol{\alpha}}_{\mathbf{f}}$ \\
\hline 90 & 45.51 & 1.0 & 1.0 & 1.0 & 1.0 & 1.0 \\
\hline \multicolumn{7}{|c|}{ Hot water heating $\mathbf{t}_{\mathbf{w}}^{\prime}=\mathbf{1 1 5}^{\circ} \mathbf{C}, \mathbf{t}_{\mathbf{w}}{ }^{\prime}=\mathbf{1 0 0}^{\circ} \mathbf{C}$} \\
\hline $\mathbf{t}_{\mathbf{f}}{ }^{\prime \prime},{ }^{\circ} \mathbf{C}$ & $\Delta \mathbf{t}_{\text {log }},{ }^{\circ} \mathbf{C}$ & $\mathbf{B}$ & $\overline{\mathbf{G}}_{\mathbf{f}}$ & $\overline{\mathbf{Q}}$ & $\overline{\mathbf{G}}_{\mathrm{w}}$ & $\overline{\boldsymbol{\alpha}}_{\mathbf{f}}$ \\
\hline 80 & 46.38 & 1.085 & 1.625 & 1.301 & 45.47 & 1.174 \\
\hline 82 & 45.17 & 1.067 & 1.416 & 1.189 & 37.71 & 1.122 \\
\hline 84 & 43.92 & 1.050 & 1.236 & 1.088 & 35.33 & 1.072 \\
\hline 86 & 42.64 & 1.033 & 1.079 & 0.993 & 33.06 & 1.025 \\
\hline 88 & 41.33 & 1.016 & 0.942 & 0.904 & 30.88 & 0.980 \\
\hline 90 & 39.98 & 1.0 & 0.824 & 0.824 & 28.80 & 0.938 \\
\hline
\end{tabular}

Taking into account the dependence of the thermal properties of fuel oil on the temperature led to a 2-fold increase in the effect of increasing the heat capacity of the heat exchanger during the transition from saturated steam to hot water. The increase in power in this case reaches $30 \%$ with a decrease in the heating temperature of fuel oil to $80^{\circ} \mathrm{C}$, the consumption of fuel oil increases by $62.5 \%$ in comparison with the use of saturated steam as a heating coolant.

\subsubsection{Turbulent regime of fuel oil flow.}

We determine the power of the heat exchanger and fuel oil flow through the heat exchanger for turbulent flow of fuel oil at the design value of its temperature at the inlet $\mathrm{t}_{\mathrm{f}}^{\prime}=40^{\circ} \mathrm{C}$, at the outlet $\mathrm{t}_{\mathrm{f}}^{\prime \prime}=80 \ldots 90^{\circ} \mathrm{C}$. The temperature of the water at the inlet of the heat exchanger is equal to $t_{w}^{\prime}=115^{\circ} \mathrm{C}$, at the outlet of the heat exchanger $\mathrm{t}_{\mathrm{w}}^{\prime \prime}=100^{\circ} \mathrm{C}$.

The transition to the turbulent flow regime for plate heat exchangers is possible at critical values of the Reynolds number $\mathrm{Re}_{\mathrm{cr}}<50$ when using turbulent inserts. In accordance with [14] for plate heat exchangers, the criterion equation of heat transfer in the turbulent regime of fuel oil flow has the form

$$
\mathrm{Nu}=0.135 \operatorname{Re}^{0.73} \operatorname{Pr}^{0.43}\left(\operatorname{Pr}_{\mathrm{f}} / \operatorname{Pr}_{\mathrm{w}}\right)^{0.25},
$$




$$
\mathrm{k} \approx \alpha_{\mathrm{f}} \square \mathrm{w}^{0.73} .
$$

The heat balance equation for fuel oil and the heat transfer equation for heating fuel oil with steam in a heat exchanger with a given geometry have the form:

$$
\mathrm{Q}_{0}=\mathrm{G}_{\mathrm{f} 0} \mathrm{c}_{\mathrm{pf} 0}\left(\mathrm{t}_{\mathrm{f} 0}^{\prime \prime}-\mathrm{t}_{\mathrm{f}}^{\prime}\right)=\mathrm{FD}\left(\mathrm{t}_{\mathrm{avf} 0}\right) \mathrm{G}_{\mathrm{f} 0}^{0.73} \Delta \mathrm{t}_{\log }^{0} \text {, }
$$

for heating fuel oil with water:

$$
\mathrm{Q}=\mathrm{G}_{\mathrm{f}} \mathrm{c}_{\mathrm{pf}}\left(\mathrm{t}_{\mathrm{f}}^{\prime \prime}-\mathrm{t}_{\mathrm{f}}^{\prime}\right)=\mathrm{FD}\left(\mathrm{t}_{\mathrm{avf}}\right) \mathrm{G}_{\mathrm{f}}^{0.73} \Delta \mathrm{t}_{\log } \text {. }
$$

The solution of the system of equations for the system of recirculation heating of fuel oil with water coolant without taking into account the dependence of the thermal properties of fuel oil on the temperature will take the form

$$
\begin{gathered}
\overline{\mathrm{G}}_{\mathrm{f}}=\left\{\left[\left(\mathrm{t}_{\mathrm{f} 0}^{\prime \prime}-\mathrm{t}_{\mathrm{f}}^{\prime}\right) \Delta \mathrm{t}_{\log }\right] /\left[\left(\mathrm{t}_{\mathrm{f}}^{\prime \prime}-\mathrm{t}_{\mathrm{f}}^{\prime}\right) \Delta \mathrm{t}_{\log }^{0}\right]\right\}^{3.704}, \\
\overline{\mathrm{Q}}=\overline{\mathrm{G}}_{\mathrm{f}}\left(\mathrm{t}_{\mathrm{f} 0}^{\prime \prime}-\mathrm{t}_{\mathrm{f}}^{\prime}\right) /\left(\mathrm{t}_{\mathrm{f}}^{\prime \prime}-\mathrm{t}_{\mathrm{f}}^{\prime}\right), \\
\bar{\alpha}_{\mathrm{f}}=\alpha_{\mathrm{f}} / \alpha_{\mathrm{f} 0}=\mathrm{Nu} / \mathrm{Nu}_{0} \approx \overline{\mathrm{G}}_{\mathrm{f}}^{0.73} .
\end{gathered}
$$

The remaining ratios (8) remain the same. Table 3 shows the results of solving the system (8), (9), (15) for heating temperatures of fuel oil in the range of $80 . . .90^{\circ} \mathrm{C}$

Table 3. The results of approximate calculations for water heating $\left(115 \ldots 100^{\circ} \mathrm{C}\right)$ for turbulent flow of the fuel oil in the channels of a plate heat exchanger.

\begin{tabular}{|c|c|c|c|c|c|}
\hline \multicolumn{7}{|c|}{ Saturated steam heating $\mathbf{t}_{\mathbf{s}}=\mathbf{1 1 5}^{\circ} \mathbf{C}, \mathbf{t}_{\mathbf{f}}{ }^{\prime}=\mathbf{4 0}^{\circ} \mathbf{C}$} \\
\hline $\mathbf{t}_{\mathbf{f}}{ }^{\circ},{ }^{\circ} \mathbf{C}$ & $\Delta \mathbf{t}_{\text {log }},{ }^{\circ} \mathbf{C}$ & $\overline{\mathbf{G}}_{\mathbf{f}}$ & $\overline{\mathbf{Q}}$ & $\overline{\mathbf{G}}_{\mathbf{s}}$ & $\overline{\boldsymbol{\alpha}}_{\mathbf{f}}$ \\
\hline 90 & 45.51 & 1.0 & 1.0 & 1.0 & 1.0 \\
\hline \multicolumn{7}{|c|}{ Hot water heating $\mathbf{t}_{\mathbf{w}}^{\prime}=\mathbf{1 1 5}^{\circ} \mathbf{C}, \mathbf{t}_{\mathbf{w}}{ }_{\mathbf{w}}=\mathbf{1 0 0}^{\circ} \mathbf{C}$} \\
\hline $\mathbf{t}_{\mathbf{f}}{ }^{\prime},{ }^{\circ} \mathbf{C}$ & $\Delta \mathbf{t}_{\text {log }},{ }^{\circ} \mathbf{C}$ & $\overline{\mathbf{G}}_{\mathbf{f}}$ & $\overline{\mathbf{Q}}$ & $\overline{\mathbf{G}}_{\mathrm{w}}$ & $\overline{\boldsymbol{\alpha}}_{\mathbf{f}}$ \\
\hline 80 & 46.38 & 2.451 & 1.961 & 69.20 & 1.924 \\
\hline 82 & 45.17 & 1.860 & 1.562 & 55.06 & 1.573 \\
\hline 84 & 43.92 & 1.407 & 1.239 & 43.88 & 1.283 \\
\hline 86 & 42.64 & 1.070 & 0.984 & 34.75 & 1.051 \\
\hline 88 & 41.33 & 0.814 & 0.782 & 27.68 & 0.861 \\
\hline 90 & 39.98 & 0.619 & 0.619 & 21.79 & 0.705 \\
\hline
\end{tabular}

Accounting for the dependence of the properties of fuel oil on its temperature is possible by introducing a multiplier for fuel oil consumption by analogy with the previously considered laminar flow regime of fuel oil

$$
\mathrm{D}\left(\mathrm{t}_{\mathrm{avf}}\right) / \mathrm{c}_{\mathrm{pf}} \square \mathrm{E}=\left(\frac{\mathrm{a}_{0}^{\mathrm{f}}\left(\mathrm{t}_{\text {avf }}\right)}{\mathrm{a}^{\mathrm{f}}\left(\mathrm{t}_{\mathrm{avf}}\right)}\right)^{0.73} \cdot\left(\frac{\mathrm{Pr}_{\mathrm{f}}}{\mathrm{Pr}_{\mathrm{w}}}\right)^{0.25} .
$$

Table 4 shows the results of the solution corresponding to the transition from the heating coolant of saturated steam to hot water for the turbulent flow

\begin{tabular}{|c|c|c|c|c|c|c|}
\hline \multicolumn{7}{|c|}{ Saturated steam heating $\mathrm{t}_{\mathrm{s}}=115^{\circ} \mathrm{C}, \mathrm{t}_{\mathrm{f}}^{\prime}=40^{\circ} \mathrm{C}$} \\
\hline $\mathbf{t}_{\mathrm{f}}^{\prime \prime},{ }^{\circ} \mathrm{C}$ & $\Delta \mathbf{t}_{\log },{ }^{\circ} \mathrm{C}$ & B & $\overline{\mathbf{G}}_{\mathrm{f}}$ & $\overline{\mathbf{Q}}$ & $\overline{\mathbf{G}}_{\mathrm{s}}$ & $\bar{\alpha}_{\mathrm{f}}$ \\
\hline 90 & 45.51 & 1.0 & 1.0 & 1.0 & 1.0 & 1.0 \\
\hline \multicolumn{7}{|c|}{ 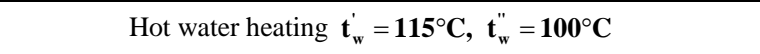 } \\
\hline $\mathbf{t}_{\mathrm{f}}^{\prime \prime},{ }^{\circ} \mathrm{C}$ & $\Delta \mathbf{t}_{\log },{ }^{\circ} \mathrm{C}$ & B & $\overline{\mathbf{G}}_{\mathrm{f}}$ & $\overline{\mathbf{Q}}$ & $\overline{\mathbf{G}}_{\mathrm{w}}$ & $\bar{\alpha}_{\mathrm{f}}$ \\
\hline 80 & 46.38 & 1.089 & 2.670 & 2.136 & 75.36 & 2.095 \\
\hline 82 & 45.17 & 1.070 & 1.990 & 1.671 & 58.91 & 1.683 \\
\hline 84 & 43.92 & 1.052 & 1.480 & 1.303 & 46.16 & 1.350 \\
\hline 86 & 42.64 & 1.034 & 1.106 & 1.017 & 35.93 & 1.087 \\
\hline 88 & 41.33 & 1.017 & 0.828 & 0.795 & 28.15 & 0.876 \\
\hline 90 & 39.98 & 1.0 & 0.619 & 0.619 & 21.79 & 0.705 \\
\hline
\end{tabular}
regime of fuel oil, taking into account the dependence of the properties of fuel oil on its temperature [15].
Table 4. The results of calculations for water heating $\left(115 \ldots 100^{\circ} \mathrm{C}\right)$ for turbulent flow of the fuel oil in the channels of a plate heat exchanger is based on the dependence of the properties of the fuel oil temperature.

It is obvious that in the turbulent flow regime, the transition from steam to water in the heat exchanger is accompanied by significantly stronger increases in fuel oil consumption by 2.67 times and the heat capacity of the heat exchanger by 2.136 times. For the selected boiler, its rated power of $2500 \mathrm{~kW}$ will limit the manifestation of this effect for the turbulent flow of fuel oil.

\section{Conclusions}

1. Warm-up in rail tank cars of fuel oil brand M100 hot water it is possible to use a plate heat exchanger M15-MFG and their analogues for the existing system of steam heating of fuel oil without reconstruction and without increasing the number of plates, while maintaining countercurrent flow heat transfer. Fuel oil flow regime is usually laminar.

2. As a heating coolant, it is proposed to use the flow of water heated in a hot-water boiler from $100^{\circ} \mathrm{C}$ to $115^{\circ} \mathrm{C}$ at a water pressure of up to 3.5 bar.

3. The consumption of heated fuel oil and the heat exchanger power at a given temperature of fuel oil at the inlet to the heat exchanger $40^{\circ} \mathrm{C}$ and the initial water temperature of $115^{\circ} \mathrm{C}$ will strongly depend on the temperature to which the fuel oil is heated.

4. At the temperature of fuel oil at the outlet of the heat exchanger $90^{\circ} \mathrm{C}$, the heat power and fuel oil consumption will be less by $17.6 \%$ compared to the heating option saturated with steam at $115^{\circ} \mathrm{C}$.

5. At the temperature of fuel oil at the outlet of the heat exchanger $80^{\circ} \mathrm{C}$, the heat exchanger power exceeds the steam heating power by $15.1 \%$. Consumption of heated fuel oil in this case is $43.8 \%$ more in comparison with steam heating.

6. Reducing the temperature of the heated fuel oil flow from 90 to $80^{\circ} \mathrm{C}$ in the transition from steam to hot water will speed up the process of heating and draining fuel oil from the tank without the reconstruction of the circulating heating oil system.

7. The obtained results in the first approximation are valid for shell and tube heat exchangers. 


\section{References}

1. Y. G. Nazmeev, Heat transfer and hydrodynamics in storage systems for liquid organic fuel and petroleum products (Moscow: Publishing house MPEI, 2005)

2. Y. G. Nazmeev, E. V. Shamsutdinov, R. F. Kamalov, Proceedings of the Russian Academy of Sciences. Power Engineering 2 52-60 (2006)

3. R. F. Kamalov, Modeling of heat transfer and development of energyefficient heat-engineering schemes for circulation heating of fuel oil for reserve fuel oil facilities of TPPs. Kand. eng. sci. diss. Kazan: Kazan ScC of RAS, Publ 155 (2006)

4. R. N. Taktashev, Development of recommendations on energy saving in the system of circulation heating of fuel oil based on numerical modeling of heat transfer in tanks (MPEI, Moscow, 2008)

5. J. Zhao, L. Wei L, H. Dong and F. Liu. Case Studies in Thermal Engineering, 7, 109 - 119 (2016)

6. V. O. Zdor, R. F. Kamalov, J. F. Karaeva and A. I. Kadiyrov. Transactions of Academenergo 1, 42-49 (2018)

7. J. V. Karaeva, V. O. Zdor, A. I. Kadyirov and E. V. Shamsutdinov. Jet mixing when heating oil and fuel oil in storage tanks E3S Web of Conferences 124, 01047 (2019)

8. M. Rahimi, A. Parvareh. Computers \& Chemical Engineering 31, 737-44 (2007)

9. P. Manjula, P. Kalaichelvi, C. Shanawaskhan, K. Dheenathayalan. Asia-Pacific Journal of Chemical Engineering 5, 544-51 (2010)

10. P. Kalaichelvi, Y. Swarnalatha1 and T. Raja. ARPN Journal of Engineering and Applied Sciences, 2, 5, 35-43 (2007)

11. P. K. Bhattacharjee, S. Kennedy, N. Eshtiaghi, R. Parthasarathy. Chemical Engineering Journal, 276, 137-44 (2015)

12. V. A. Petrushchenkov. News of heat supply, 2, 1720 (2017)

13. Pat. 2112733 RU, Int. Cl.6 B 65 G 69/20//B 65 D $88 / 74$. Method of heating and draining fuel oil from railway tanks / Levchenko E.L., applicant and proprietor. - N 96119886/13; appl. 15.10.1996 ; public. 10.06.1998, Bull. №3 (1996)

14. The design of the heat stations. SP 41-101-95

15. Z. I. Geller, Fuel oil as fuel (Nedra, Moscow, 1965) 